\title{
Genetic Profile of Total Body Energy Content of Holstein Cows in the First Three Lactations
}

\author{
G. Banos, ${ }^{1}$ S. Brotherstone, ${ }^{2,3}$ and M. P. Coffey ${ }^{2}$ \\ ${ }^{1}$ Department of Animal Production, School of Veterinary Medicine, Aristotle University of Thessaloniki, \\ Box 393, GR-54124 Thessaloniki, Greece \\ ${ }^{2}$ Sustainable Livestock Systems, Scottish Agricultural College, Bush Estate, Penicuik, \\ EH26 OPH, United Kingdom \\ ${ }^{3}$ Institute of Evolutionary Biology, University of Edinburgh, Ashworth Laboratories, King's Buildings, \\ Edinburgh, EH9 3JT, United Kingdom
}

\begin{abstract}
Weekly total body energy content (TBEC) was calculated for 444 Holstein cows in their first 3 lactations. These calculations were based on body lipid and protein changes predicted from weekly changes in body condition score and live weight of each cow. In first lactation, cows lost TBEC during the initial $8 \mathrm{wk}$, regained it by wk 22 , and continued to build up their reserves until wk 37. Cows started lactations 2 and 3 with considerable reserves from the dry period that they used during the first 13 wk of lactation. Variance components for TBEC were estimated using random regression analysis allowing for heterogeneous residual variance. The genetic variance increased within each lactation, suggesting that the genetic component becomes more important as lactation progresses. The genetic correlations between very early (wk 1 to 4 ) and later stages of first lactation were near zero but they increased considerably between later lactation stages. Genetic correlations between TBEC on wk 5 of first lactation and the remainder of this lactation ranged from 0.64 for the more distant weeks to 0.99 for the immediately subsequent weeks. Genetic correlations with TBEC in second lactation were moderately high ( 0.68 to 0.70 ) for the early weeks ( 1 to 8 ) and decreased gradually to 0.56 for weeks at the end of lactation. For third lactation, these estimates ranged from 0.53 to 0.63 . Genetic correlation estimates of TBEC in wk 12 of first lactation with subsequent first-lactation weeks varied from 0.79 to 0.99 , whereas they ranged from 0.65 to 0.77 and from 0.57 to 0.68 in second and third lactations, respectively. The genetic correlation between TBEC in later weeks of first lactation and the rest of productive life increased as first lactation progressed, but the improvement diminished. Weekly genetic evaluations for first-lactation
\end{abstract}

Received January 14, 2005

Accepted March 18, 2005.

Corresponding author: G. Banos; e-mail: banos@vet.auth.gr.
TBEC were used to predict second- and third-lactation energy content. The accuracy of these predictions increased with progressing weeks in first lactation, but about three-fourths of the improvement occurred by wk 5. Our results suggest that TBEC calculated after a month from the first calving may give useful information about the future energy content of a cow.

(Key words: total body energy content, genetic variation, lactation, dairy cattle)

Abbreviation key: LWT = live weight, $\mathbf{T B E C}=$ total body energy content.

\section{INTRODUCTION}

Dairy cows must get sufficient energy from feed intake to meet their main physiological requirements such as milk production, growth, reproduction, maintenance, and general activity. The body energy content of a cow, at any point in time, depends on energy taken in, energy dispensed, and energy carried over from previous lactation stages. If energy dispensed exceeds energy reserved, then the cow is in negative energy balance and must catabolize body tissue to meet its energy requirements. An animal in prolonged negative energy balance exhibits cumulative body energy loss and becomes prone to health and reproductive problems, and considerable financial loss (Beam and Butler, 1998; De Vries et al., 1999; Kendrick et al., 1999; Collard et al., 2000; De Vries and Veerkamp, 2000; Reist et al., 2000; Veerkamp et al., 2000). Furthermore, carryover effects frequently result in increasing negative energy balance and associated recurring health and fertility problems across the cow's productive life (Coffey et al., 2001).

The energy profile of a cow changes over time reflecting, among other things, changes in live weight (LWT) and BCS. These traits correspond to one or more energy-demanding physiological activities of the cow. Live weight is associated with a cow's growth and pregnancy status, whereas BCS is associated with the level of metabolizable lipid reserves. Coffey et al. (2001) com- 
bined preadjusted LWT and BCS data for the same cows to calculate energy balance from predicted body lipid and protein weight changes. The advantage of using these traits is that they can become available in a commercial dairy cattle population. Body condition score is often part of the routine cow classification program, whereas LWT may be predicted from linear conformation traits (Koenen and Groen, 1998; Coffey et al., 2003). Therefore, energy indicators based on these traits can be included in population-wide genetic evaluation schemes (Coffey et al., 2003). Accumulating body lipid and protein changes predicted from BCS and live weight may provide useful measures of total body energy content (TBEC) over the cow's productive life. Studies on the genetic profile of this trait are largely missing from the literature.

The objectives of the present study were a) to estimate the genetic variance of TBEC of cows in their first 3 lactations, and b) to develop prediction equations of second- and third-lactation energy content from firstlactation data.

\section{MATERIALS AND METHODS}

\section{Data}

Data were 39,539 weekly records of 444 Holstein cows in their first 3 lactations. These cows had known pedigree, had been kept at the Langhill Dairy Cattle Research Centre in Scotland between 1990 and 2002, and had participated in feed and selection trials. In these trials, cows had been grouped according to diet (high vs. low concentrates in a TMR) and genetic merit (selected vs. control line) within diet. Milk yield and feed intake were recorded daily. Body condition score and LWT records were obtained weekly for these animals.

Total body energy content was calculated based on predicted body protein and lipid changes from weekly BCS and LWT records. Coffey et al. (2001, 2003) described this procedure in detail. Briefly, body protein and lipid content were predicted from BCS and LWT after adjusting the latter for gut fill and weight of conceptus. Dry matter intake and diet metabolizable energy content, estimated from daily feed intake, were used to calculate gut fill. Weight of conceptus was estimated based on days of pregnancy, using the formula of Bruce et al. (1984). Body protein and lipid change were estimated by subtracting the current estimate weekly from the previous week. Cumulative change was calculated by adding the new to the sum of previous estimates. The effective energy system proposed by Emmans (1994) was then used to obtain effective energy required for cumulative body protein and lipid change;
Table 1. Descriptive statistics of total body energy content (in MJ) by 305-d lactation.

\begin{tabular}{lrlll}
\hline Lactation & Mean & SD & Minimum & Maximum \\
\hline 1 & -123 & 1611 & -5082 & 10,021 \\
2 & 416 & 2251 & -5061 & 12,783 \\
3 & 1108 & 2362 & -4470 & 12,695 \\
All & 363 & 2097 & -5082 & 12,783 \\
\hline
\end{tabular}

the sum of the 2 yielded TBEC. Table 1 gives descriptive statistics of TBEC for a 305-d lactation.

\section{(Co)variance Component Estimation}

The following model was used to analyze weekly TBEC records:

$$
\begin{gathered}
\mathrm{Y}_{\mathrm{ijklmn}}=\left(\mathrm{YW}_{\mathrm{i}}+\mathrm{GF}_{\mathrm{j}}+\mathrm{a}_{1} \cdot \text { age }+\mathrm{a}_{2} \cdot \mathrm{age}^{2}\right. \\
\left.+\sum_{\mathrm{n}=0}^{4} \mathrm{~b}_{\mathrm{n}} \mathrm{P}_{\mathrm{n}} \mathrm{W}_{\mathrm{m}}+\sum_{\mathrm{n}=0}^{4} \mathrm{c}_{\mathrm{ln}} \mathrm{P}_{\mathrm{n}} \mathrm{W}_{\mathrm{m}}+\mathrm{PE}_{\mathrm{l}}\right)_{\mathrm{k}}+\mathrm{e}_{\mathrm{ijklmn}}
\end{gathered}
$$

where $Y_{\mathrm{ijklmn}}=$ TBEC record of cow 1 in week $\mathrm{m}$ of lactation $\mathrm{k} ; \mathrm{YW}_{\mathrm{i}}=$ fixed effect of year-week of observation $\mathrm{i} ; \mathrm{GF}_{\mathrm{j}}=$ fixed effect of selection line by feeding group interaction $\mathrm{j} ; \mathrm{a}_{1}$ and $\mathrm{a}_{2}=$ linear and quadratic regression coefficients on age at calving expressed as a deviation from the mean; $\mathrm{W}_{\mathrm{m}}=$ week $\mathrm{m}$ of lactation $\mathrm{k} ; \mathrm{b}_{\mathrm{n}}=$ fixed regression coefficient associated with the overall curve; $c_{\mathrm{ln}}=$ random regression coefficient associated with cow $1 ; P_{n}=n$th Legendre polynomial of week $\mathrm{m}\left(\mathrm{n}=\right.$ order of Legendre polynomial); $\mathrm{PE}_{1}=$ random permanent environment effect associated with cow l; and $\mathrm{e}_{\mathrm{ijklmn}}=$ random residual term.

At first, all effects in model 1 were nested within lactation $\mathrm{k}$, which is equivalent to conducting a withinlactation analysis. Higher-order permanent environment effects were also fitted; however, the system failed to converge. This was true even when the order of the cow (genetic) effect was reduced. Therefore, the final within-lactation model included a linear regression on permanent environment. Estimates of the random regression coefficients from the within-lactation analysis were used to calculate variance components per week of lactation.

Subsequently, all data were analyzed jointly in an across-lactation analysis. Estimates from this analysis were used to derive covariance components between weeks of different lactations, which is equivalent to treating the 3 lactations as different traits. In this case, however, the permanent environment effect had to be removed from model 1 because of estimability and convergence problems. Apparently, data were insufficient to allow inclusion of all effects and simultaneous esti- 
mation of all parameters in the across-lactation analysis.

In either case, complete cow pedigree information available from the Langhill Dairy Cattle Research Centre was included to account for genetic relationships between animals. In this respect, a total of 5758 animals were included in the pedigree file. Furthermore, depending on lactation stage, 7 measurement error classes were defined per lactation as follows: wk 1 to 2,3 to 4,5 to 8,9 to 12,13 to 16,17 to 20 , and $\geq 21$. Different residual variances were estimated per measurement error class but residual variance was assumed homogeneous within class. Covariances between classes were assumed to be zero. All analyses were conducted with the ASREML software package (Gilmour et al., 2002).

\section{Prediction of TBEC in Second and Third Lactation from First Lactation}

Weekly animal solutions (genetic evaluations) of first-lactation TBEC obtained from the within-lactation analysis with model 1 were used to develop prediction equations of second- and third-lactation TBEC with model 2:

$$
\begin{gathered}
\mathrm{Y}_{\mathrm{ijklmn}}=\mathrm{E}_{\mathrm{i}}+\mathrm{G}_{\mathrm{j}}+\mathrm{F}_{\mathrm{l}}+\mathrm{a}_{\mathrm{l}} \cdot \operatorname{age}+\mathrm{W}_{\mathrm{m}} \\
+\left(\mathrm{b}_{\mathrm{s}} \cdot \mathrm{S}\right)_{\mathrm{m}}+\sum_{\mathrm{n}=0}^{4} \mathrm{c}_{\mathrm{kn}} \mathrm{P}_{\mathrm{n}} \mathrm{W}_{\mathrm{m}}+\mathrm{e}_{\mathrm{ijklmn}}
\end{gathered}
$$

where $\mathrm{Y}_{\mathrm{ijk} k \mathrm{mn}}=$ TBEC record of cow $\mathrm{k}$ in week $\mathrm{m}$ of lactation 2 or $3 ; \mathrm{E}_{\mathrm{i}}=$ fixed effect of year of observation $\mathrm{i} ; \mathrm{G}_{\mathrm{j}}=$ fixed effect of selection line $\mathrm{j} ; \mathrm{F}_{\mathrm{l}}=$ fixed effect of feeding group $\mathrm{l} ; \mathrm{a}_{1}=$ linear regression coefficient on age at calving; $\mathrm{W}_{\mathrm{m}}=$ week $\mathrm{m}$ of lactation 2 or $3 ; \mathrm{b}_{\mathrm{s}}=$ fixed regression coefficient on genetic evaluation (S) of cow $\mathrm{k}$ for any week of first lactation, nested within week $\mathrm{m}$ of lactation 2 or $3 ; c_{\mathrm{kn}}=$ random regression coefficient associated with cow $\mathrm{k} ; \mathrm{P}_{\mathrm{n}}=\mathrm{nth}$ Legendre polynomial of week $\mathrm{m}$ of lactation 2 or 3 ; and $\mathrm{e}_{\mathrm{ijk} k \mathrm{mn}}=$ random residual term. Model 2 was applied separately to second- and third-lactation records. In each case, sequential analyses were conducted to derive TBEC predictions from all first-lactation weeks to all second- and third-lactation weeks.

To evaluate the accuracy of these predictions, the data set was randomly split into 2 independent, mutually exclusive subsets. Model 2 was separately applied to either subset and regression coefficients derived were then used in the other subset of data to calculate predicted TBEC. Predicted records were compared with actual observations using the root mean square error, mean absolute difference, and their product-moment correlation.

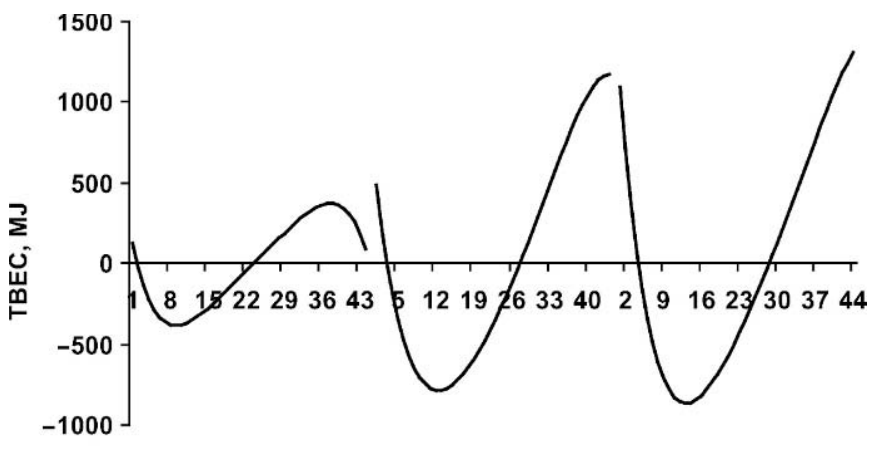

Week of lactation

Figure 1. Least square mean phenotypic values of total body energy content (TBEC) by week in the first 3 lactations.

\section{RESULTS AND DISCUSSION}

\section{Profile of TBEC}

Least square means for phenotypic values of TBEC by week of lactation across the first 3 lactations are shown in Figure 1. These represent mean energy content estimated from cumulative body protein and lipid changes as they accumulate over time since the cows' first calving, adjusted for all effects in model 1. No mean trend appeared across the 3 lactations. In first lactation, cows lost TBEC during the initial $8 \mathrm{wk}$, gained it back by wk 22 , and continued to build up their reserves until wk 37, before returning to their original energy state by the end of lactation. This drop in TBEC after wk 37 may be attributed to advanced pregnancy state combined with the fact that first-lactation cows may still be growing, thereby demanding additional energy. Cows started lactations 2 and 3 with considerable reserves from the dry period that they used during the first $13 \mathrm{wk}$ of lactation, before regaining it by the end of lactation. Coffey et al. (2002) observed similar trends in cumulative body energy state predicted from animal solutions for BCS and LWT. In the study of Coffey et al. (2002), cumulative energy was defined in reference to the onset of each lactation.

\section{(Co)variance Component Estimation}

In this study, (co)variance components were estimated with a random regression model on weeks of lactation fitted as a fifth-order Legendre polynomial. Lower order ( 1 to 4 ) polynomials were also fitted but tests based on the log likelihood ratio and Schwartz's Bayesian information criterion (accounting for number of parameters to be estimated and size of the data set) were significant $(P<0.05)$ attesting to the need for a higher order. The 5 Eigen values of the first-lactation (co)variance structure accounted for 94.3, 3.6, 0.2, 1.2, 


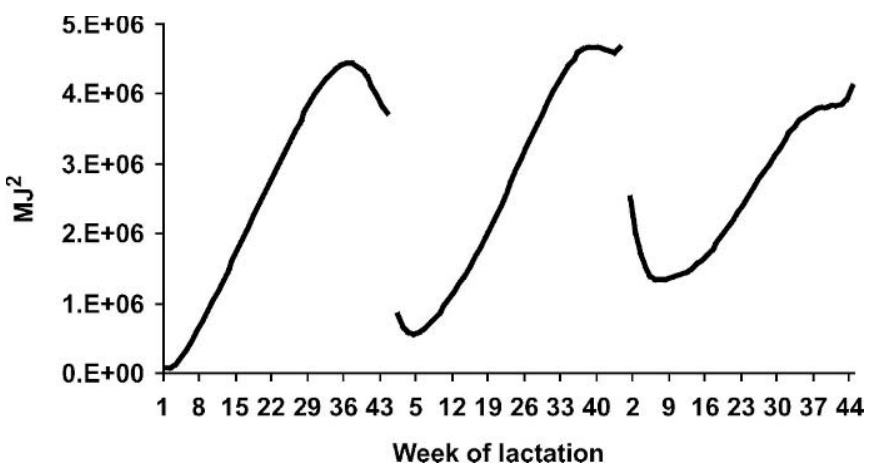

Figure 2. Estimated genetic variance of total body energy content by week in the first 3 lactations (SE lactation $1=51,800$ to 184,700 $\mathrm{MJ}^{2}$; SE lactation $2=90,430$ to $345,600 \mathrm{MJ}^{2}$; SE lactation $3=100,900$ to $368,300 \mathrm{MJ}^{2}$ ).

and $0.7 \%$ of the total variation, respectively. For second lactation, they accounted for $90.9,5.1,2.0,1.2$, and $0.8 \%$ of the variance, respectively. Finally, for third lactation, the 5 Eigen values accounted for $86.9,6.2,4.4,1.5$, and $1.0 \%$ of the variance, respectively. Although in all cases, the first 4 Eigen values accounted for approximately $99 \%$ of the variance, there was still about $1 \%$ left for the fifth. This, along with the significance of the 2 log likelihood tests, led us to include the fifth order in the analysis. Furthermore, the number of inflection points on the curve was at least 2 in first lactation and one each in second and third lactations (Figure 1), suggesting that an order of 5 is biologically explainable. Coffey et al. (2001, 2003) also considered fifth-order Legendre polynomials to model BCS and LWT, and then combined solutions from these analyses to derive and study daily energy balance measures. It should be noted that fitting fifth-order Legendre polynomials is computationally feasible with large (national) data analyses of LWT and BCS records (Coffey et al., 2003; Banos et al., 2004).

\section{Within-Lactation Analysis}

Figure 2 illustrates genetic variance estimates for TBEC by week of lactation across the first 3 lactations. In general, genetic variation increased with time in all lactations, suggesting that the animal genetic component becomes more important as lactations progress. Standard errors indicated that all genetic variance estimates were significantly different from zero $(P<0.05)$, except for estimates in the first $3 \mathrm{wk}$ of first lactation. This is probably due to the fact that the trait was defined as cumulative energy since the cow's first calving, and the genetic components had not been sufficiently expressed this early in the animal's productive life.
Table 2. Estimated residual variance of total body energy content (in $\mathrm{MJ}^{2}$; $\mathrm{SE}$ in parentheses) by measurement error class and lactation.

\begin{tabular}{|c|c|c|c|}
\hline $\begin{array}{l}\text { Weeks of } \\
\text { lactation }\end{array}$ & Lactation 1 & Lactation 2 & Lactation 3 \\
\hline 1 to 2 & $75,210 \quad(6347)$ & $277,973(25,110)$ & $362,759 \quad(36,941)$ \\
\hline 3 to 4 & 109,455 & 114,695 & 154,534 \\
\hline 5 to 8 & $83,673 \quad(35$ & $67(40$ & $41(6296)$ \\
\hline 9 to 12 & $67,526(2786)$ & $87,989(4045)$ & $123,753(6409)$ \\
\hline 13 to 16 & $87,335 \quad(3518)$ & $119,108 \quad(5273)$ & 101,740 \\
\hline 17 to 20 & 89,043 (3521) & 96,979 (4351) & 111,568 (5686) \\
\hline$\geq 21$ & $104,310(1816)$ & $122,863(2396)$ & $141,642(3058)$ \\
\hline
\end{tabular}

Residual variance estimates (Table 2) increased from first to later lactations, suggesting that unsystematic sources of variation may play a bigger role in later stages of an animal's productive life. Residual variance showed no marked trend within the first lactation. In lactations 2 and 3, residual variance was greatest at the beginning of lactation, possibly indicating the effect of varying dry periods. Estimates decreased in wk 3 and 4 and then remained constant for the rest of either lactation.

Weekly heritability estimates were calculated as ratios of genetic to total phenotypic variance and ranged from 0.25 to 0.94 (SE 0.03 to 0.88 ) in first lactation, between 0.24 and 0.72 (SE 0.03 to 0.10 ) in second, and from 0.40 to 0.67 (SE 0.03 to 0.07 ) in third lactation. In all cases, heritability estimates increased as lactations were progressing, reaching their highest values toward the end of lactation. For most first-lactation estimates, standard errors ranged between 0.03 and 0.32 . However, standard errors for the first 3 wk were 0.60 to 0.88 and were associated with the lowest heritability estimates, rendering them nonsignificantly different from zero. This is consistent with the profile of the genetic variance estimate (Figure 2) and supports the notion that TBEC, defined as cumulative energy since the onset of the cow's productive life, can be characterized genetically only after the first few weeks of first lactation have elapsed.

In general, heritability estimates obtained here were expected to be high because they were based on data from a single experimental farm with a controlled environment; therefore, unsystematic environmental variation is expected to be small relatively to large field data studies. Another possible explanation of the magnitude of these estimates is the fact that permanent environment was only fitted as an intercept in model 1. Attempts to increase the order of the regression were associated with failure to converge. Perhaps some unaccounted-for portion of permanent environmental variance was incorporated into the genetic variance estimate. Furthermore, LWT and BCS, the 2 determinant traits of TBEC in this study, also exhibited high herita- 


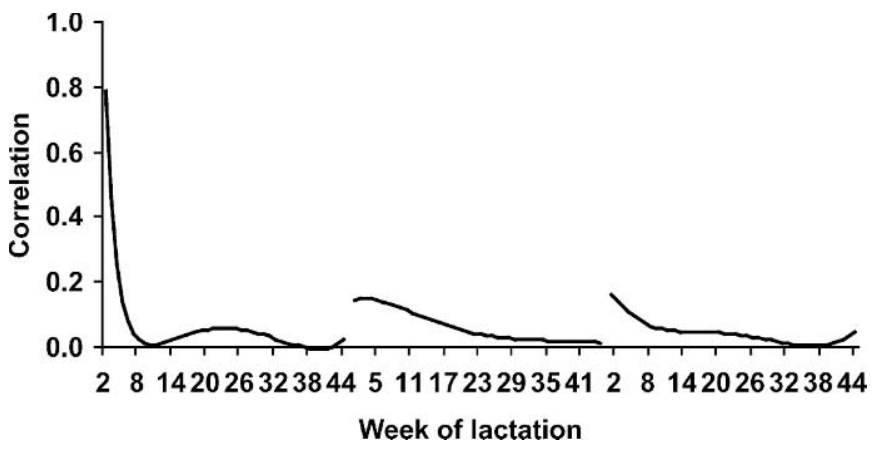

Figure 3. Estimated genetic correlation between total body energy content in wk 1 of first lactation and later weeks of all 3 lactations.

bility in a previous analysis of data from the same farm (Coffey et al., 2001). In that study, heritability estimates ranged between 0.56 and 0.83 for first-lactation LWT and from 0.38 to 0.81 for first-lactation BCS, increasing for either trait with progressing lactation (Coffey et al., 2001). In another study of experimental farm data, Veerkamp et al. (2000) reported high heritability estimates for BW (0.48 to 0.55) and DM intake (0.61), both of which are related to energy content. Estimates obtained from experimental farm data are expected to be higher than estimates based on field data analysis, because the latter are potentially subject to more sources of environmental variation. For example, in a study based on commercial farm data from Ireland, Berry et al. (2002) reported heritability estimates of 0.27 to 0.37 for BCS and 0.39 to 0.48 for BW. No heritability estimates were found in the literature for TBEC; therefore, no direct pertinent comparisons can be made with results of this study.

\section{Across-Lactation Analysis}

Genetic correlations between wk 1, 5, and 12 of first lactation on one hand and all subsequent weeks in all 3 lactations on the other were estimated and are shown in Figures 3, 4, and 5, respectively. Total body energy content in wk 1 post first calving had very low genetic correlation with TBEC in the rest of the cow's productive life (Figure 3). This is probably due to the trait definition. The implication is that records taken this early in a cow's productive life are uninformative regarding future TBEC. After the first month of the first lactation, TBEC records started showing an increasing correlation with energy content in later life. The genetic correlation between TBEC on wk 5 of first lactation and the remainder of this lactation ranged from 0.64 with the more distant weeks to 0.99 with the immediately subsequent weeks (Figure 4). Genetic correlation estimates with TBEC in the second lactation were moder-

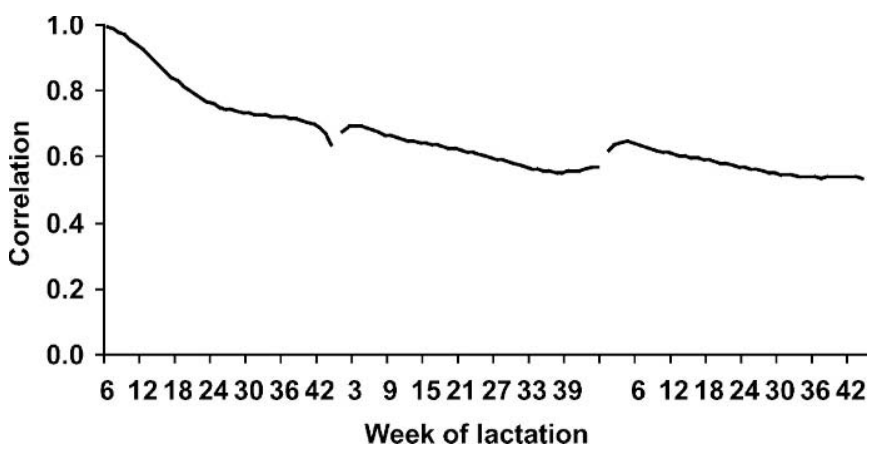

Figure 4. Estimated genetic correlation between total body energy content in wk 5 of first lactation and later weeks of all 3 lactations.

ately high (0.68 to 0.70$)$ for the early weeks ( 1 to 8$)$ and decreased gradually to 0.56 for weeks at the end of lactation (Figure 4). For third lactation, these estimates ranged from 0.53 to 0.63 (Figure 4). Genetic correlation estimates of TBEC in wk 12 of first lactation with subsequent first lactation weeks varied from 0.79 to 0.99 , whereas they ranged between 0.65 and 0.77 and between 0.57 and 0.68 with second and third lactation, respectively (Figure 5). The genetic correlation between TBEC after wk 12 of the first lactation with the rest of productive life steadily increased as the first-lactation record approached the end of lactation, but the improvement diminished.

Figure 6 depicts the genetic correlation estimates between TBEC in the $44 \mathrm{wk}$ of first lactation and wk 13 of second and third lactation. Week 13 coincides with the nadir of TBEC in these lactations (Figure 1), which may be associated with reduced fertility and increased disease susceptibility. Genetic correlation estimates increased as the stage of first lactation progressed, reaching the maximum value in wk 27 to 37 ; however, the increase was especially steep during the first $5 \mathrm{wk}$, slowing down considerably afterwards. In fact, the ge-

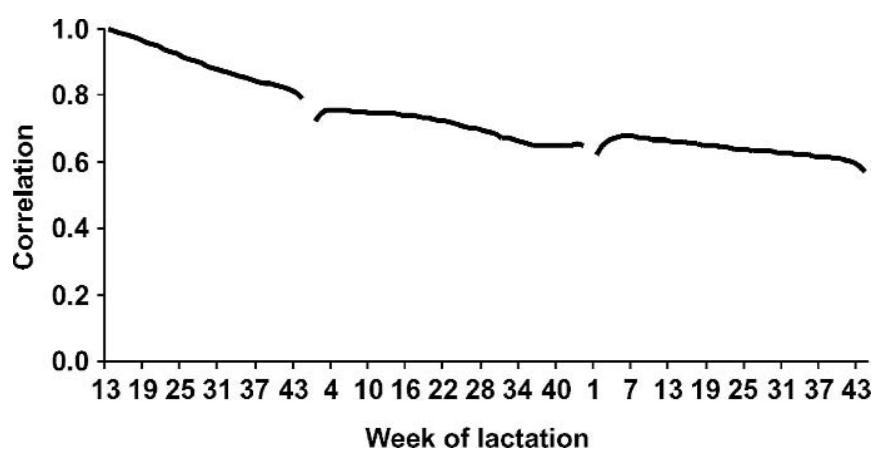

Figure 5. Estimated genetic correlation between total body energy content in wk 12 of first lactation and later weeks of all 3 lactations. 


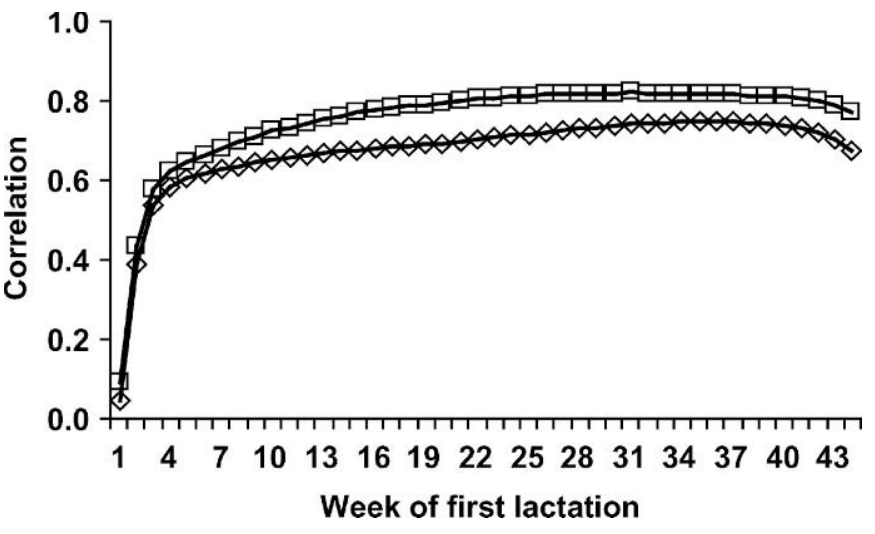

Figure 6. Estimated genetic correlation between total body energy content in the $44 \mathrm{wk}$ of first lactation and wk 13 (week of minimum body energy content) in second $(\square)$ and third $(\diamond)$ lactations.

netic correlation between wk 5 of first lactation and wk 13 of second and third lactation was $76 \%$ of the maximum genetic correlation in either case. These results suggest that TBEC records taken a month or more after first calving may give useful information about the future energy content of a cow.

As with heritability, genetic correlation estimates between TBEC at various stages of a cow's lactation are missing from the literature. However, there are reports on the 2 traits (BCS and LWT) that were used here to calculate TBEC. Coffey et al. (2001) analyzed data from the same experimental farm as this study and reported genetic correlation estimates ranging between 0.77 and 1.00 for LWT and from 0.17 to 1.00 for BCS. In another study based on field data, Banos et al. (2004) estimated genetic correlations ranging between 0.50 and near unity for BCS. In all cases, estimates were highest for consecutive DIM and decreased for more distant stages of lactation, a trend that was also observed in the present study.

\section{Prediction of TBEC in Second and Third Lactation from First Lactation}

When weekly animal genetic evaluations for firstlactation TBEC were used to predict second and third lactation TBEC, the proportion of the variance accounted for by the predictor ranged from 0.14 to 0.63 and 0.14 to 0.53 , respectively (Figure 7 ). These were the average values obtained by comparing predicted and actual values in 2 independent datasets. In each case, regression coefficients calculated on one data set were applied to the other, and vice versa. The proportion of the variance accounted for was calculated as the square of the product-moment correlation between predicted and actual TBEC. Genetic evaluations for wk

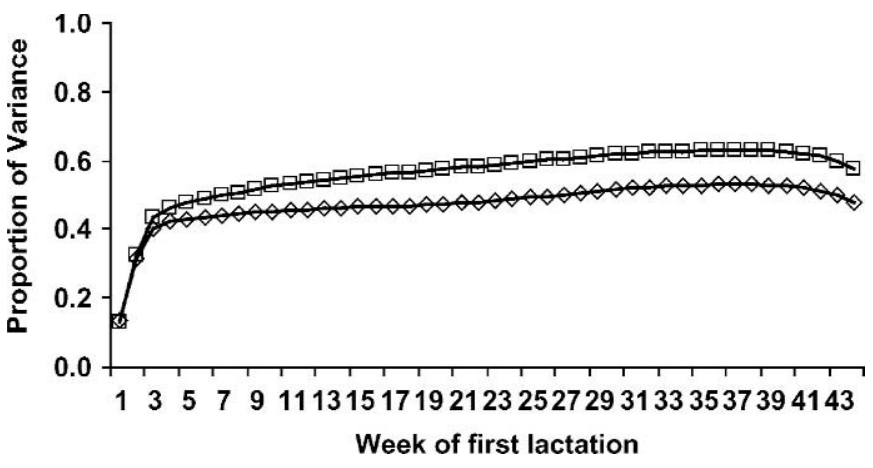

Figure 7. Proportion of total phenotypic variance of total body energy content in second $(\square)$ and third $(\diamond)$ lactations predicted from weekly first-lactation animal genetic evaluations.

37 in first lactation yielded the most accurate predictions for both second and third lactation. However, the improvement in prediction accuracy diminished rapidly after wk 5 of the first lactation. These results are corroborated by the mean absolute difference between actual second or third lactation records and predicted values from first-lactation genetic evaluations (Figure 8). These, too, are averages from deriving predictions in 2 independent data sets. As the first lactation progressed, mean absolute difference decreased, reaching its lowest in wk 37 and 36 for second and third lactation predictions, respectively. However, about three-fourths of the improvement occurred by wk 5. Very similar results were obtained from the root mean square error calculation between observed and predicted TBEC (not shown).

All factors included in model 2 had a significant $(P$ $<0.05$ ) effect on TBEC in second and third lactation. In separate analyses, lower Legendre polynomial orders were fitted or the cow effect was removed altogether. However, the goodness of fit, evaluated by the log likelihood and the residual variance estimate, was signifi-

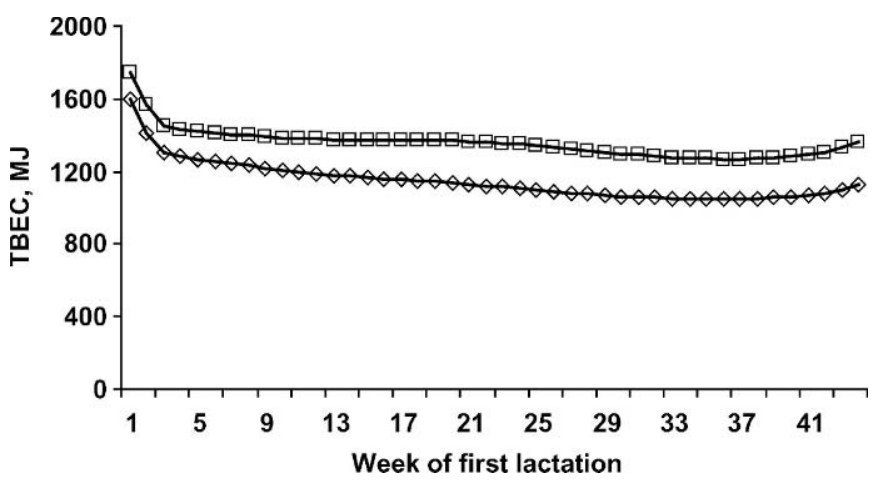

Figure 8. Mean absolute difference between actual total body energy content (TBEC) in second $(\square)$ and third $(\diamond)$ lactations and predicted from weekly first-lactation animal genetic evaluations. 
cantly $(P<0.05)$ impaired. In addition, the accuracy of prediction, assessed by the comparison of actual and predicted values, was reduced.

The following equation is shown for illustration purposes and was derived for the prediction of TBEC in wk 13 of the second lactation (coinciding with the lowest TBEC value in this lactation) from genetic evaluation for wk 5 of first lactation, using model 2 and all available data:

$$
\begin{aligned}
\text { TBEC }= & 1221.45-25.77 \times \text { age }+1.19 \\
& \times \text { proof }+ \text { line }+ \text { diet }
\end{aligned}
$$

where TBEC is total body energy content in wk 13 of second lactation, age is the age of the cow at second calving, and proof is the genetic evaluation of the cow for wk 5 in first lactation. The variable "line" had a value of 0 for control and -387.90 for selected line animals. The variable "diet" had a value of 0 for animals in the low and 57.26 for animals in the high-concentrate diet group. The constant (1221.45) is the average solution for all year effects plus the intercept solution for wk 13. Similar equations were derived for predicting TBEC in any second and third lactation week from genetic evaluations for any week of first lactation.

In this study, model 2 included the effects of group and diet to account for the fact that data used were from a selection experiment. Both effects were significant suggesting that, ideally, different predictions should be derived depending on feeding and selection practices on the farm. However, any relevant information is likely to be missing from field data and would be unavailable should the proposed methodology be applied on a national scale. Therefore, new equations will have to be derived for future TBEC predictions, reflecting the overall feeding and selection practices prevalent on commercial farms.

In the present study, TBEC was calculated based on weekly phenotypic records for BCS and LWT. Previously, Coffey et al. (2003) used animal solutions from univariate random regression analyses of these 2 traits to calculate daily and lactation energy measures. The advantage of their approach was that sources of systematic variation pertinent to either BCS or LWT were separately dealt with. However, TBEC calculated in this study is an unregressed energy measure exhibiting its full phenotypic variation, allowing for more accurate genetic analysis and estimation of variance components.

Total body energy content calculated in this study described the cow's energy changes as they accumulate over its productive life. In the United Kingdom, the 2 component traits (BCS and LWT) are available in a commercial cow monitoring program, where BCS is routinely assessed on first-lactation heifers and LWT can be predicted from linear conformation traits. Coffey et al. (2003) reported correlation of 0.92 between actual LWT and predicted from classification scores of firstlactation Holsteins. Although an estimate of gut fill may still be needed for the final calculations of TBEC and feed intake records are absent from population data, experimental values can be used to fill in the missing information. Therefore, TBEC of first-lactation heifers can be routinely calculated and genetically evaluated, offering a useful selection tool. It should be noted that, in such case, genetic evaluations would have to be based on a sire model with repeated observations (daughters) per sire (Coffey et al., 2003; Banos et al., 2004), because no repeated records per cow will be available. Furthermore, based on results from the present study, weekly first-lactation genetic evaluations can also be used to predict second- and third-lactation TBEC of Holstein sire daughters in herds participating in the national linear classification scheme.

Having established the genetic profile of TBEC, it is important to understand its true relationship with health and reproductive traits. Knowing the genetic correlation of TBEC in first lactation with disease frequency and fertility throughout the cow's productive life would facilitate selection decisions for the genetic improvement of these important functional traits.

\section{CONCLUSIONS}

Results from this study suggest that genetic evaluations for first-lactation TBEC can be routinely calculated. This can assist in the identification and selection of animals less prone to lose energy content during their productive life. Furthermore, genetic evaluations for TBEC in weeks after the first 4 wk in first lactation may be used to derive accurate predictions of TBEC in second and third lactation.

\section{ACKNOWLEDGMENTS}

This work was financed by Avoncroft Sires Ltd., BOCM Pauls Ltd., CIS, Cogent, Dartington Cattle Breeding Trust, Genus Breeding Ltd., Holstein UK, National Milk Records plc, Royal Society for the Prevention of Cruelty to Animals, and Department for Environment, Food, and Rural Affairs, in the Sustainable Livestock Production LINK program, and based on data collected under a grant from Scottish Executive Environment and Rural Affairs Department. Contribution of data from the Langhill Dairy Cattle Research Centre, Scotland, stewarded by Ross McGinn, is gratefully acknowledged. 


\section{REFERENCES}

Banos, G., S. Brotherstone, and M. P. Coffey. 2004. Evaluation of body condition score measured throughout lactation as an indicator of fertility in dairy cattle. J. Dairy Sci. 87:2669-2676.

Beam, S. W., and W. R. Butler. 1998. Energy balance, metabolic hormones, and early postpartum follicular development in dairy cows fed prilled lipid. J. Dairy Sci. 81:121-131.

Berry, D. P., F. Buckley, P. Dillon, R. D. Evans, M. Rath, and R. F. Veerkamp. 2002. Genetic parameters for level and change of body condition score and body weight in dairy cows. J. Dairy Sci. 85:2030-2039.

Bruce, J. M., P. J. Broadbent, and J. H. Topps. 1984. A model of the energy system of lactating and pregnant cows. Anim. Prod. 38:351-362.

Coffey, M. P., G. C. Emmans, and S. Brotherstone. 2001. Genetic evaluation of dairy bulls for energy balance traits using random regression. Anim. Sci. 73:29-40.

Coffey, M. P., G. Simm, and S. Brotherstone. 2002. Energy balance profiles for the first three lactations of dairy cows estimated using random regression. J. Dairy Sci. 85:2669-2678.

Coffey, M. P., G. Simm, W. G. Hill, and S. Brotherstone. 2003. Genetic evaluations of dairy bulls for daughter energy balance profiles using linear type scores and body condition score analyzed with random regression. J. Dairy Sci. 86:2205-2212.

Collard, B. L., P. J. Boettcher, J. C. M. Dekkers, D. Peticlerc, and L. R. Schaeffer. 2000. Relationships between energy balance and health traits of dairy cattle in early lactation. J. Dairy Sci. 83:2683-2690.
De Vries, M. J., S. Van Der Beek, L. M. T. E. Kaal-Lansbergen, W. Ouweltjes, and J. B. M. Wilmink. 1999. Modelling of energy balance in early lactation and the effect of energy deficits in early lactation on first detected estrus postpartum in dairy cows. J. Dairy Sci. 82:1927-1934.

De Vries, M. J., and R. F. Veerkamp. 2000. Energy balance of dairy cattle in relation to milk production variables and fertility. J. Dairy Sci. 83:62-69.

Emmans, G. C. 1994. Effective energy: A concept of energy utilization applied across species. Br. J. Nutr. 71:801-821.

Gilmour, A. R., B. J. Gogel, B. R. Cullis, S. J. Welham, and R. Thompson. 2002. ASREML User Guide. Release 1.0 VSN International Ltd., Hemel Hempstead, UK.

Kendrick, K. W., T. L. Bailey, A. S. Garst, A. W. Pryor, A. Ahmadzadeh, R. M. Akers, W. E. Eyestone, R. E. Pearson, and F. C. Gwazdauskas. 1999. Effects of energy balance on hormones, ovarian activity, and recovered oocytes in lactating Holstein cows using transvaginal follicular aspiration. J. Dairy Sci. 82:1731-1740.

Koenen, E. P. C., and A. F. Groen. 1998. Genetic evaluation of body weight of lactating Holstein heifers using body measurements and conformation traits. J. Dairy Sci. 81:1709-1713.

Reist, M., A. Koller, A. Busato, U. Kupfer, and J. W. Blum. 2000. First ovulation and ketone body status in the early postpartum period of dairy cows. Theriogenology 54:685-701.

Veerkamp, R. F., J. K. Oldenbroek, H. J. Van der Gaast, and J. H. J. Van der Werf. 2000. Genetic correlation between days until start of luteal activity and milk yield, energy balance and live weights. J. Dairy Sci. 83:577-583. 